\title{
Formation of the Dehydrogenases for Lactate, Ethanol and Butanediol in the Strictly Aerobic Bacterium Alcaligenes eutrophus
}

\author{
By H. G. SCHLEGEL* AND D. VOLLBRECHT \\ Institut für Mikrobiologie der Universität und Institut für Mikrobiologie der \\ Gesellschaft für Strahlen- und Umweltforschung $m b H$, München, \\ in Göttingen, Grisebachstrasse 8, 3400 Göttingen, Federal Republic of Germany
}

(Received 27 July 1979; revised 19 October 1979)

\begin{abstract}
Lactate, ethanol and butanediol were excreted when Alcaligenes eutrophus was exposed to severely restricted aeration. This indicated the presence of dehydrogenases which are not normally present in aerobically grown cultures of this strictly aerobic bacterium. When grown in the presence of measurable dissolved oxygen concentrations. A. eutrophus strain N9A and a double mutant defective in the formation of poly-3-hydroxybutanoic acid and in the utilization of 3-hydroxybutanoate did not synthesize alcohol, lactate or butanediol dehydrogenases. However, when bacteria were subsequently incubated for 10 to $25 \mathrm{~h}$ under restricted aeration conditions that permitted respiration rates of only about 3 to $15 \%$ of the maximum value, the above enzymes were formed with specific activities up to $0.75 \mu \mathrm{mol}$ $\min ^{-1}$ (mg protein $)^{-1}$. The identity of metabolites excreted as well as the nature of the enzymes formed could be correlated with the distinctive relative respiration rates enforced on the bacteria during incubation.

The results indicate that $A$. eutrophus contains genetic information which is not expressed under ordinary cultural conditions. The significance for retention of the dormant genetic material in strictly aerobic bacteria is discussed.
\end{abstract}

\section{INTRODUCTION}

Significant amounts of metabolites such as ethanol, lactic acid, succinic acid, butanediol, butyric acid, 3-hydroxybutyric acid and others were excreted by the strictly aerobic bacterium Alcaligenes eutrophus when the supply of oxygen was restricted (Vollbrecht et al., 1978; Vollbrecht \& Schlegel, 1978). The nature of the excreted metabolite was specifically related to the relative respiration rate (RRR), i.e. the ratio of the actual respiration rate imposed on the cells by restricting the aeration rate to the maximum respiration rate which the cells expressed under conditions of unrestricted oxygen supply during exponential growth (Vollbrecht et al., 1979).

$$
\text { Relative respiration rate }(\mathrm{RRR})=100 \times \frac{\text { Restricted rate of respiration }}{\text { Maximum cellular respiration rate }}
$$

This ratio has previously been used to describe the condition under which Brevibacterium lactofermentum produces various amino acids (Akashi et al., 1977) and was designated as 'oxygen satisfaction' (Hirose et al., 1978).

Some of the products excreted by $A$. eutrophus are normal intermediates of the metabolism of strict aerobes, e.g. 2-oxoglutarate, cis-aconitate, succinate and 3-hydroxybutanoate. Others, such as ethanol, lactate, butanediol, butanoate and formate, are fermentative 
products which are not normal intermediary metabolites of a strictly aerobic bacterium, so enzymes involved in their formation are not expected to be present. This study deals with determinations of specific enzyme activities in bacteria incubated under conditions which promote the excretion of metabolites.

\section{METHODS}

Organisms. Alcaligenes eutrophus strain N9A (wild-type), its mutant N9A-PHB-02 (DSM 1348), which is defective in the synthesis and accumulation of poly-3-hydroxybutanoic acid (PHB), and mutant N9A-

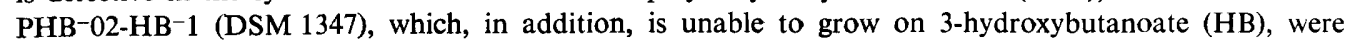
described previously (Vollbrecht et al., 1978; Vollbrecht \& Schlegel, 1979).

Media, growth and incubation conditions. Bacteria were grown in mineral media containing gluconate and ammonium as carbon and nitrogen source, respectively, in 41 fermenters at $30^{\circ} \mathrm{C}, \mathrm{pH} 7 \cdot 0$, and an aeration rate of $185 \mathrm{ml}$ air $\mathrm{min}^{-1} \mathrm{l}^{-1}$ (Vollbrecht et al., 1978, 1979). After exponential growth to an $A_{436}$ of about $10 \cdot 0\left(2 \mathrm{~g}\right.$ dry wt $\left.1^{-1}\right)$ with an unrestricted oxygen supply, the oxygen consumption rate of the suspension was measured and the aeration rate was decreased to adjust the oxygen consumption rate to the desired value. Samples of bacteria were taken at intervals, washed in minimal medium, resuspended in the same medium and stored frozen at $-20^{\circ} \mathrm{C}$. Each sample was examined for possible contamination by streaking on plates containing either mineral agar or, in addition, glucose, fructose or 3-hydroxybutanoate as substrate and incubating the plates in an atmosphere of $\mathrm{H}_{2} / \mathrm{O}_{2} / \mathrm{CO}_{2}$ or air, respectively.

Determinations of excreted metabolites and of oxygen. The excreted metabolites were quantitatively determined by gas-liquid chromatography (Vollbrecht et al., 1978).

The rate of oxygen consumption by the cell suspension was determined by comparing the flow rates as well as the composition of gas mixtures entering and leaving the fermenters (Vollbrecht et al., 1979).

Preparation of extracts. Bacteria for enzyme determinations were broken by ultrasonication. The frozen suspension ( $4 \mathrm{ml} ; 40 \mathrm{mg} \mathrm{dry} \mathrm{wt} \mathrm{ml}^{-1}$ ) was thawed and sonicated for 3 min using an MSE (150 W) ultrasonic disintegrator with a probe of $9.5 \mathrm{~mm}$ diam. Extracts low in NADH oxidase activity were obtained by centrifuging the sonicate for $20 \mathrm{~min}$ at $10000 \mathrm{rev} \cdot \mathrm{min}^{-1}$ and $60 \mathrm{~min}$ at $40000 \mathrm{rev} . \mathrm{min}^{-1}$ in the Vacufuge (Heraeus-Christ, Osterode, F.R.G.). Low molecular weight compounds were removed by passing the extracts through columns of Sephadex G-25.

Determination of enzyme activities. The activities of lactate dehydrogenase (EC 1.1.1.27), alcohol dehydrogenase (EC 1.1.1 1), butanediol dehydrogenase (EC 1.1.1.4), malate dehydrogenase (EC 1.1 1. 37) and hydrogenase (hydrogen: $\mathrm{NAD}^{+}$oxidoreductase; $\mathrm{EC} 1.12 .1 .2$ ) were determined by measuring changes in $A_{365}$, with NAD(H), in a Zeiss-PL4 Filter-photometer according to the assay procedures described in Bergmeyer (1970). All assays were done at $30^{\circ} \mathrm{C}$. Lactate dehydrogenase was assayed in $2.65 \mathrm{ml} 0.1 \mathrm{M}$ potassium phosphate buffer, $\mathrm{pH} 7.0,0.1 \mathrm{ml} 2.5$ mM-sodium pyruvate, $0.05 \mathrm{ml} 10 \mathrm{~mm}-\mathrm{NADH}$ and $0.2 \mathrm{ml}$ extract. The assay for alcohol dehydrogenase contained $2.5 \mathrm{ml}$ semicarbazide/pyrophosphate buffer $(0.1$ M-sodium pyrophosphate and $8 \mathrm{~mm}$-semicarbazide. $\mathrm{HCl}, \mathrm{pH} 8 \cdot 9), 0 \cdot 1 \mathrm{ml}$ ethanol, $0.2 \mathrm{ml} 30 \mathrm{~mm}-\mathrm{NAD}, 0.01 \mathrm{ml}$ $0.6 \mathrm{M}$-glutathione and $0.2 \mathrm{ml}$ extract. Butanediol dehydrogenase was assayed in $2.5 \mathrm{ml} 0.1 \mathrm{M}$-phosphate buffer, pH 7.0, $0 \cdot 1 \mathrm{ml}$ butanediol ( $1 \mathrm{ml}$ dissolved in $10 \mathrm{ml}$ water), $0.2 \mathrm{ml} 30 \mathrm{~mm}-\mathrm{NAD}$ and $0.2 \mathrm{ml}$ extract (HöhnBentz \& Radler, 1978). Malate dehydrogenase was assayed in $2.65 \mathrm{ml} 0 \cdot 1 \mathrm{M}$-phosphate buffer, $\mathrm{pH} 7 \cdot 0$, $0.1 \mathrm{ml} 15 \mathrm{~mm}$-oxaloacetate, $0.05 \mathrm{ml} 10 \mathrm{~mm}$-NADH and $0.2 \mathrm{ml}$ extract diluted $1: 50$ in $0.1 \mathrm{M}$-phosphate buffer. Hydrogenase was measured as described by Schneider \& Schlegel (1976). Acetohydroxyacid synthase (EC 4.1.3.18) was determined according to Umbarger \& Brown (1958) as modified by Reh \& Schlegel (1969), measuring acetoin with creatine and 2-naphthol.

Protein was determined according to Beisenherz et al. (1953). The unit of enzyme activity is defined as that which catalyses the conversion of $1 \mu \mathrm{mol}$ substrate $\mathrm{min}^{-1}$.

Chemicals. Butanediol was obtained from BDH, Sephadex G-25 from Pharmacia, nutrients and substrates from Merck, and biochemicals from Boehringer.

\section{RESULTS}

Alcaligenes eutrophus excreted various metabolites when aerobically grown cultures were incubated for 10 to $40 \mathrm{~h}$ with a restricted supply of oxygen. After a comparative study, $A$. eutrophus strain N9A and mutant PHB-02 defective in the synthesis of poly-3-hydroxy-

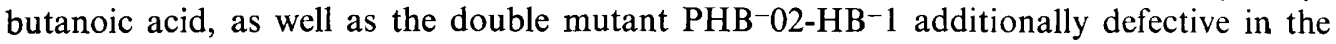
utilization of 3-hydroxybutanoate, were chosen for studies of the excretory process, because they were easy to handle and excreted large quantities of metabolites (Vollbrecht et al., 
Table 1. Relative respiration rate-dependent excretion of metabolites by Alcaligenes eutrophus N9A-PHB-02 and N9A-PHB-02-HB-1

The minimum and maximum limits of the relative respiration rates at which the metabolite was detected are given. The optimum represents that relative respiration rate at which the maximum amount of the metabolite was found. (Results summarized from Vollbrecht et al., 1979.)

Excretory product
None
2-Oxoglutarate
2-Oxo-3-methylbutanoate
cis-Aconitate
3-Hydroxybutanoate
Butanoate
Acetate
$\mathrm{H}_{2}$
Formate
Succinate
2-Methylpropanoate
2-Methylbutanoate
3-Methylbutanoate
meso-2,3-Butandiol
Acetoin
DL-2,3-Butandiol
2-Methylpropan-1-ol
Ethanol
1-Propanol
Lactate

\begin{tabular}{cccc}
\multicolumn{2}{c}{ Relative respiration rate (\%) } & $\begin{array}{c}\text { Maximum } \\
\text { amount } \\
\left(\mathrm{g} \mathrm{l}^{-1}\right)\end{array}$ \\
26 & $\begin{array}{c}\text { Optimum } \\
\text { Minimum }\end{array}$ & Maximum & - \\
22 & 50 & 88 & $6 \cdot 2$ \\
15 & 27 & 60 & $1 \cdot 8$ \\
4 & 21 & 27 & $3 \cdot 4$ \\
2 & 11 & 30 & $3 \cdot 4$ \\
2 & 7 & 14 & $1 \cdot 2$ \\
2 & 7 & 10 & $3 \cdot 1$ \\
2 & 6 & 10 & ND \\
2 & 6 & 22 & $6 \cdot 2$ \\
5 & $5 \cdot 5$ & 14 & $2 \cdot 6$ \\
5 & $5 \cdot 5$ & 6 & $0 \cdot 07$ \\
5 & $5 \cdot 5$ & 6 & $0 \cdot 025$ \\
2 & $5 \cdot 5$ & 6 & $0 \cdot 08$ \\
$4 \cdot 5$ & 5 & 8 & $3 \cdot 9$ \\
2 & 5 & 6 & $0 \cdot 23$ \\
1 & $4 \cdot 4$ & 8 & $2 \cdot 4$ \\
1 & $2 \cdot 4$ & 5 & $0 \cdot 11$ \\
1 & $2 \cdot 4$ & 8 & $1 \cdot 8$ \\
1 & $2 \cdot 4$ & 8 & $0 \cdot 04$ \\
& $2 \cdot 4$ & 5 & $0 \cdot 8$
\end{tabular}

ND, Not determined.

1979). Bacteria were routinely grown on gluconate at $30^{\circ} \mathrm{C}$ to an $A_{436}$ of $10\left(2 \mathrm{~g}\right.$ dry wt $\left.1^{-1}\right)$ before the aeration rate was decreased. The respiration rates were determined from the oxygen consumption rates of bacterial cell suspensions in the fermenters, and relative respiration rates were then calculated. A typical pattern of the excretion of fermentation products at a relative respiration rate of $3 \%$ is presented in Fig. 1. The pattern of extracellular products could be correlated with the relative respiration rate. At each relative respiration rate a number of metabolites were excreted; only the major metabolite is listed in Table 1.

It was of interest to know whether enzymes such as lactate, alcohol and butanediol dehydrogenases, which are required for the synthesis of lactate, ethanol and butanediol, respectively, were formed constitutively in the bacterial strain investigated, or whether they were synthesized only under conditions of restricted oxygen supply. In the latter case, they might be synthesized coordinately below a distinct threshold relative respiration rate or they could be regulated independently.

Lactate dehydrogenase, alcohol dehydrogenase and butanediol dehydrogenase were either not present in aerobically grown $A$. eutrophus N9A-PHB $-02-\mathrm{HB}^{-} 1$ or, if detectable, their specific activities were very low (Table 2). Between 10 and $25 \mathrm{~h}$ after the respiration rate had been decreased to about $5 \%$ of the unrestricted rate, significant activities of all three enzymes were detected. In contrast, the constitutive enzyme malate dehydrogenase was detected under all incubation conditions.

Comparison of the increases in specific activities of the lactate, alcohol and butanediol dehydrogenases in bacteria that had been incubated at different relative respiration rates (Table 2) indicated a dependence of enzyme formation on the degree of respiratory restriction. At RRR values of 5.5 and $14.5 \%$ the enzymes were present while at an RRR of $40 \%$ 


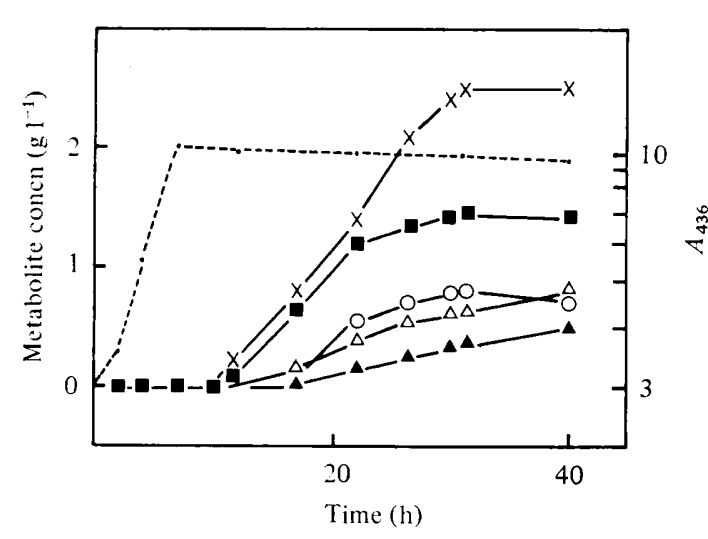

Fig. 1

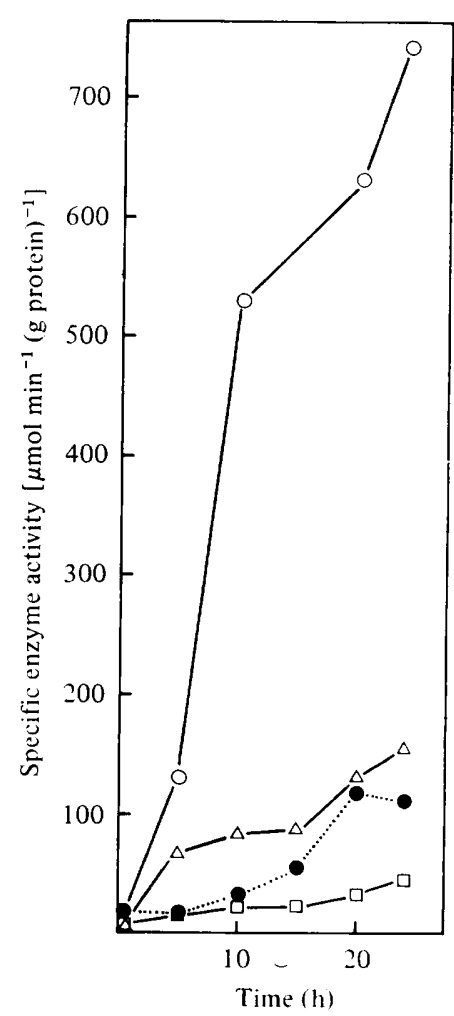

Fig. 2

Fig. 1. Relative respiration rate-dependent excretion of metabolites by Alcaligenes eutrophus N9A-PHB $-02-\mathrm{HB}^{-1}$. Bacteria were grown as described in Methods. When growth $\left(A_{436},---\right)$ ceased due to exhaustion of ammonium, the oxygen supply was restricted to allow a respiration rate of $3 \%$ of that at the end of the exponential growth phase. About $4 \mathrm{~h}$ after restriction of oxygen supply, metabolites were formed: $\times$, succinate; $\mathbf{\square}$, ethanol; $\bigcirc$, lactate; $\triangle$, meso-2,3-butanediol; $\Delta$, DL-2,3-butanediol.

Fig. 2. Increase of specific activities of enzymes in Alcaligenes eutrophus N9A-PHB-02-HB-1 grown aerobically on gluconate up to an $A_{\mathbf{4 3 6}}$ of 10 and then incubated with a restricted oxygen supply allowing a relative respiration rate of $3 \%$. Enzymes: $O$, lactate dehydrogenase; $\triangle$, butanediol dehydrogenase; $\bigcirc$, hydrogenase; $\square$, alcohol dehydrogenase.

they were absent. A distinct threshold RRR between 15 and $40 \%$, which has so far not been determined exactly, appears to be necessary to derepress the formation of these enzymes.

The kinetics of enzyme formation were determined in an experiment with the same double mutant PHB $-02-\mathrm{HB}^{-1}$ incubated at a RRR of $3 \%$ (Fig. 2). Synthesis of the enzymes occurred slowly, lasting at least $24 \mathrm{~h}$; this is consistent with the kinetics of the excretion of the respective metabolites (Fig. 1). Excretion started about $5 \mathrm{~h}$ after restriction of the oxygen supply and continued for about $30 \mathrm{~h}$. During the excretory phase the metabolites were

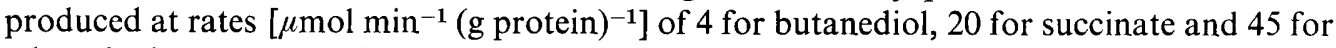
ethanol; these rates are in proportion to the specific activities of the respective enzymes.

Activities of other enzymes which are specifically involved in the synthesis of the excreted products were also determined. Acetohydroxyacid synthase is known to be present in $A$. eutrophus strain $\mathrm{H} 16$ and to be involved in the isoleucine-valine-leucine biosynthetic pathways (Reh \& Schlegel, 1969). In the double mutant N9A-PHB-02-HB-1 it was detected with moderate specific activity [about $100 \mu \mathrm{mol} \mathrm{min} \mathrm{m}^{-1}$ (g protein) ${ }^{-1}$ ] in exponentially grown cells, as well as in cells incubated under restricted oxygen supply. These results indicate that 


\section{Table 2. Specific activities of enzymes in Alcaligenes eutrophus N9A-PHB-02-HB-1}

Results for three separate experiments are shown. In each experiment, bacteria were grown aerobically on gluconate to an $A_{436}$ of about $10\left(2.0 \mathrm{~g}\right.$ dry wt $\left.\mathrm{l}^{-1}\right)$ when the first $(0 \mathrm{~h})$ sample was taken. They were then incubated with a restricted oxygen supply allowing the relative respiration rate (RRR) indicated. The second and third samples were taken at the times indicated.

Specific enzyme activity $\left(\mu \mathrm{mol} \min ^{-1}(\mathrm{~g} \text { protein })^{-1}\right]$

\begin{tabular}{|c|c|c|c|c|c|c|c|c|c|}
\hline \multirow[b]{2}{*}{ Enzyme } & & & \\
\hline & $0 \mathrm{~h}$ & $17 \mathrm{~h}$ & $23 \mathrm{~h}$ & $0 \mathrm{~h}$ & $16 \mathrm{~h}$ & $23 \mathrm{~h}$ & $\mathrm{Oh}$ & $18 \mathrm{~h}$ & $25 \mathrm{~h}$ \\
\hline Lactate dehydrogenase & $1 \cdot 26$ & 175 & 115 & 0 & 392 & 54 & $<1$ & $<1$ & $<1$ \\
\hline Alcohol dehydrogenase & $6 \cdot 8$ & 18 & 22 & 3 & 27 & 33 & 5 & 2.6 & $2 \cdot 1$ \\
\hline Butanediol dehydrogenase & 1.8 & 45 & 36 & $2 \cdot 5$ & 74 & 202 & $3 \cdot 5$ & $5 \cdot 3$ & $6 \cdot 3$ \\
\hline Malate dehydrogenase & 6310 & 7550 & 10415 & 13640 & 13980 & 15500 & 1490 & 1870 & 1750 \\
\hline Acetohydroxyacid synthase & 120 & 86 & 96 & ND & ND & ND & 107 & 94 & 81 \\
\hline Hydrogenase & 2 & 9 & 17 & 151 & 171 & 212 & 122 & 134 & 115 \\
\hline
\end{tabular}

the enzyme is formed constitutively. In most experiments the specific activity of acetohydroxyacid synthase exceeded that of butanediol dehydrogenase. These observations are consistent with the assumption that the biosynthetic acetohydroxyacid synthase is involved in butanediol synthesis and provides its precursor, acetoin.

The $\mathrm{NAD}^{+}$-reducing hydrogenase (hydrogen:NAD ${ }^{+}$oxidoreductase) was of interest since in $A$. eutrophus $\mathrm{H} 16$ it is apparently synthesized not only during autotrophic growth under an atmosphere of $\mathrm{H}_{2} / \mathrm{O}_{2}$ but also under heterotrophic conditions (Eberhardt, 1966). The details of its regulation are not yet clear and oxygen limitation during growth was among the causative conditions suspected. The present measurements, carried out with strain N9A and mutants derived therefrom, served to exclude severe restriction of the oxygen supply as a decisive causative factor in hydrogenase synthesis under heterotrophic conditions. However, the hydrogenase present may be involved in the production of trace or moderate amounts of hydrogen which were found during incubation at 5 to $7 \%$ relative respiration rates (Vollbrecht et al., 1979). The reversibility of the hydrogenase reaction, and the production of $\mathrm{H}_{2}$ from NADH by the purified enzyme from $A$. eutrophus $\mathrm{H} 16$, has been demonstrated recently (Schneider \& Schlegel, 1976). Manometric assays did not indicate the presence of formate hydrogenlyase in the bacterial extracts of the double mutant of strain N9A.

The rates of excretion and yields of metabolites by the double mutant N9A-PHB-02-HB -1 exceeded those of the single mutant N9A-PHB-02 or the wild-type N9A of $A$. eutrophus. These differences are reflected by the specific activities of the fermentation enzymes. The single mutant (Table 3) and the wild-type strain (not shown) exhibited similar patterns of formation of lactate, alcohol and butanediol dehydrogenases. The specific activities of these enzymes were almost zero in bacteria grown exponentially under unrestricted oxygen supply and reached moderate values in bacteria incubated under conditions of restricted respiration. However, the specific enzyme activities were lower than in the double mutant. This indicated that the degree of derepression of enzyme formation is affected by the mutational lesion, the block in poly-3-hydroxybutanoic acid synthesis. For comparison, the specific enzyme activities have also been measured in strain $\mathrm{H} 16$ of $A$. eutrophus and its PHB-free mutant PHB-4. The results resembled those obtained with strain N9A and suggest that the formation of the fermentation enzymes is promoted by the deficiency in PHB synthesis. This observation in turn is important for considering the regulatory events leading to enzyme derepression. 
Table 3. Specific activities of enzymes in Alcaligenes eutrophus N9A-PHB-02

Bacteria were grown and treated as described in the legend to Table 2. The relative respiration rate was $6.3 \%$.

\begin{tabular}{l}
\multicolumn{1}{c}{ Enzyme } \\
Lactate dehydrogenase \\
Alcohol dehydrogenase \\
Butanediol dehydrogenase \\
Malate dehydrogenase \\
Acetohydroxyacid synthase \\
Hydrogenase
\end{tabular}

\section{Enzyme}

Lactate dehydrogenase Alcohol dehydrogenase Malate dehydrogenase Hydrogenase

\begin{tabular}{crr}
\multicolumn{3}{c}{$\begin{array}{c}\text { Specific enzyme activity } \\
{\left[\mu \text { mol min }^{-1}(\text { (g protein })^{-1}\right]}\end{array}$} \\
$\overbrace{0 \mathrm{~h}}^{-18 \mathrm{~h}}$ & \multicolumn{1}{c}{$24 \mathrm{~h}$} \\
$<1$ & 190 & 35 \\
$2 \cdot 6$ & 25 & 25 \\
$0 \cdot 8$ & 90 & 125 \\
4400 & 6006 & 12600 \\
84 & 31 & 52 \\
$<1$ & $<1$ & $<1$
\end{tabular}

\section{DISCUSSION}

The ability of Alcaligenes eutrophus strain N9A-PHB-02-HB-1 to synthesize lactate, alcohol and butanediol dehydrogenases under conditions of restricted oxygen supply has been positively correlated with the excretion of the metabolites: both are dependent on incubation at enforced low respiration rates. This ability to synthesize fermentation enzymes and excrete fermentation products is not confined to A. eutrophus N9A. Fermentation products have recently been detected in Paracoccus denitrificans, Pseudomonas acidovorans and Pseudomonas delafieldii (Vollbrecht \& El-Nawawy, 1980) and the enzymes have been detected in Paracoccus denitrificans, Pseudomonas denitrificans and A. eutrophus H16 (H. G. Schlegel \& M. Meyer, unpublished results) maintained under conditions in which the oxygen supply was severely limited. These unexpected observations indicate that the genetic information for fermentation enzymes, which is not expressed under ordinary culture conditions, is present in a variety of strictly aerobic bacteria.

The formation of the fermentation enzymes and the production of lactate, ethanol and butanediol by $A$. eutrophus are probably the result of various successive regulatory events. The change in the NADH/NAD ${ }^{+}$ratio may be involved as the primary metabolic signal (Harrison, 1976). The sequence of events is a matter of speculation. The NADH/NAD ${ }^{+}$ ratio may directly cause inhibition of various enzymes which would result in the accumulation of intermediary metabolites; the latter may subsequently function at the genetic level to derepress the formation of fermentation enzymes. This assumption is necessary to explain why the relative respiration rate at which derepression occurs is different for each enzyme.

The ability of strictly aerobic bacteria to form fermentation enzymes may be useless and an evolutionary relic. There are many examples of the retention of dormant genetic material in the genome which one might expect to be eliminated as an unnecessary burden (Riley \& Anilionis, 1978). On the other hand, fermentation enzymes may be of ecological significance and confer a selective advantage to strictly aerobic bacteria when temporarily exposed to anoxic conditions. The recognition of the conditions necessary for expression of the fermentation genes provides an experimental approach to the identification of these 'silent' genes and study of their significance.

The authors highly appreciate the excellent technical assistance of Maria Meyer and Armgard Janczikowski, and thank Dr D. Tempest for valuable suggestions. The study has been supported by Förderungsmittel des Landes Niedersachsen. 


\section{REFERENCES}

AKashi, K., Shibai, H. \& Hirose, Y. (1977). Effect of oxygen supply on L-valine fermentation. Journal of Fermentation Technology 55, 364-368.

Beisenherz, G., Bolze, H. J., Bücher, T., CzoK, R., Garbade, K. H. \& Meyer-Arendt, E. (1953). Diphosphofructose-Aldolase, Phosphoglyceraldehyd-Dehydrogenase, Glycerophosphat-Dehydrogenase und Pyruvat-Kinase aus Kaninchenmuskulatur in einem Arbeitsgang. Zeitschrift für Naturforschung 8b, 555-577.

BergmeYer, H.U. (1970). Methoden der Enzymatischen Analyse, vol. 1, 2nd edn. Weinheim: Verlag Chemie.

EBERHARDT, U. (1966). Über das Wasserstoff aktivierende System von Hydrogenomonas H16. II. Abnahme der Aktivität bei heterotrophem Wachstum. Archiv für Mikrobiologie 54, 115-124.

HARRISON, D. E. F. (1976). The regulation of respiration rate in growing bacteria. Advances in Microbial Physiology 14, 243-313.

Hirose, A., Sano, K. \& Shibai, H. (1978). Amino acids. In Annual Reports on Fermentation Processes, vol. 2, pp. 155-178. London: Academic Press.

HöHn-Bentz, H. \& RAdLeR, F. (1978). Bacterial 2,3-butanediol dehydrogenases. Archives of Microbiology 116, 197-203.

Reh, M. \& Schlegel, H. G. (1969). Die Biosynthese von Isoleucin und Valin in Hydrogenomonas H16. Archiv für Mikrobiologie 67, 110-127.

Riley, M. \& ANilionis, A. (1978). Evolution of the bacterial genome. Annual Review of Microbiology 32, 519-560.

Schneider, K. \& Schlegel, H. G. (1976). Purification and properties of soluble hydrogenase from
Alcaligenes eutrophus H16. Biochimica et biophysica acta 452, 66-80.

UMBARGER, H. E. \& Brown, B. (1958). Isoleucine and valine metabolism in Escherichia coli. VIII. The formation of acetolactate. Journal of Biological Chemistry 233, 1156-1160.

Volbbrecht, D. \& Schlegel, H. G. (1978). Excretion of metabolites by hydrogen bacteria. II. Influences of aeration, $\mathrm{pH}$, temperature, and age of cells. European Journal of Applied Microbiology and Biotechnology 6, 157-166.

Vollbrecht, D. \& Schlegel, H. G. (1979). Excretion of metabolites by hydrogen bacteria. III. D(-)-3-Hydroxybutanoate. European Journal of Applied Microbiology and Biotechnology 7, 259-266.

Vollbrecht, D. \& El Nawawy, M. A. (1980). Restricted oxygen supply and excretion of metabolites. I. Pseudomonas spec. and Paracoccus denitrificans. European Journal of Applied Microbiology and Biotechnology (in the Press).

Vollbrecht, D., El Nawawy, M. A. \& Schlegel, H. G. (1978). Excretion of metabolites by hydrogen bacteria. I. Autotrophic and heterotrophic fermentations. European Journal of Applied Microbiology and Biotechnology 6, 145-155.

Vollbrecht, D., Schlegel, H. G., Stoschek, G. \& JANCZIKowski, A. (1979). Excretion of metabolites by hydrogen bacteria. IV. Respiration rate-dependent formation of primary metabolites and of poly-3-hydroxybutanoate. European Journal of Applied Microbiology and Biotechnology 7, 267-276. 